Received 6 October 2020 Accepted 20 January 2021

Link to DOI:

10.25220/WNJ.V05.11.0010

Journal Website: www.worldnutrijournal.org

\section{Take-out food frequency was associated with energy intake among mothers of young children in urban slum area in North Jakarta}

\author{
Fitya Safira Birahmatika, ${ }^{1}$ Dian Novita Chandra, ${ }^{1}$ Luh Ade Ari Wiradnyani ${ }^{2}$ \\ 1. Department of Nutrition, Faculty of Medicine, Universitas Indonesia, Dr. Cipto Mangunkusumo \\ Hospital, Jakarta, Indonesia \\ 2. Southeast Asian Ministers of Education Organization Regional Center for Food and Nutrition \\ (SEAMEO RECFON) Pusat Kajian Gizi Regional (PKGR)
}

\begin{abstract}
Background: Inadequate energy intake was prevalent among women of reproductive age, which may contribute to poor diet. Having great concern towards health and nutrition may play a role in shaping eating habit and food-related behavior to achieve a healthy diet. This study aims to examine the association between health concern and energy intake, while considering other factors such as cooking frequency and having food away from home.

Methods: This cross-sectional study was carried out in an urban slum area in Jakarta, involving 233 mothers of young children through consecutive sampling. Data was collected through interview. Health concern was assessed using General Health Interest Scale (GHIS) questionnaire. Energy intake was obtained by 24-hour dietary recall in two non-consecutive days. Consumer Behavior Questionnaire (CBQ) was used to assess frequency of cooking and having food away from home. All statistical analysis was performed using SPSS Version 20.

Results: Energy intake of most subjects did not meet the recommendation, with median of 1,396 $\mathrm{kcal} /$ day. Health concern among the subjects had median of 32 out of 48 . There was no significant correlation between health concern and energy intake $(r=-0.067, P$-value $=0.309)$. The frequency of having take-out food was a significant predictor of the energy intake ( $B=7.497, P$-value $=0.028)$. Additionally, a significant negative correlation between health concern and having take-out food was found $(r=-0.141, P$-value $=0.032$ ).

Conclusions: Having take-out food was associated with energy intake. Provision of health and nutrition information in the food stores might help to increase health concern to shape a healthier diet. Thus, a collaborative effort targeting both food sellers and customers is essential.
\end{abstract}

Keywords energy intake, diet, women, health concern, health interest, take-out food 


\section{Introduction}

Suboptimal diet was observed in global population, characterized by high consumption of sugarsweetened beverage, processed meats, and sodium, contrasting with the consumption of fruits, vegetables, whole grains and legumes failed to meet the recommendation. ${ }^{1}$ Given that the obesity rates were higher among women than men, ${ }^{2}$ a healthy diet is an essential aspect for women in reproductive age to prepare for pregnancy and child bearing. However, inadequate energy intake was apparently common in women of reproductive age, including adolescent girls and pregnant women. ${ }^{3,4}$ According to Indonesian Total Diet Study 2014 (TDS 2014), more than half adults in Indonesia failed to meet the recommended energy intake. Jakarta as the capital city had the highest mean energy intake for both men and women. However, the energy intake recommendation was still not met. ${ }^{5}$ Adequacy is one of the elements comprising diet quality. Thus, inadequate energy intake may contribute to poor diet. Particularly for the child-bearing women, mother's diet was known to be a predictor for the child's diet. ${ }^{6}$

Diet is a multidimensional topic, which involves individual and environmental factors. Previous studies had highlighted the evidence of the environment, where food stores availability in urban slum neighborhood significantly contributes to energy-dense food consumption. In urban slum areas, purchasing ready-to-eat food rather than cooking was also a common practice done by mothers, who usually were the primary food provider at home. ${ }^{7,8}$ Being the main food provider means that mothers have control over choosing food and the preparation process, which is a part of food environment at household level. Having a particular concern towards health and nutrition might be a driver to practice healthier behavior related to food and diet. Previous studies have shown that women generally displayed greater interest towards health, ${ }^{9,10}$ thus they were more likely to comply to dietary recommendation. ${ }^{11}$ Additionally, having health concern was associated with food choice and meal planning. ${ }^{12,13}$

To author knowledge, health concern was rarely assessed in relation with dietary behavior and dietary outcomes especially in Indonesian setting. Knowledge about health and nutrition was more common, yet usually the results show a moderate and good degree of knowledge. ${ }^{7,14}$ Given the growing evidence of obesity prevalence and dietary patterns in urban slum areas, ${ }^{7,15}$ exploring the perceived concern towards health might contribute to design intervention program to improve not only knowledge, but to shape a healthier food environment. Therefore, this study aimed to assess the relationship between health concern and energy intake among women of reproductive age, particularly mothers of young children, while considering other factors such as cooking frequency and having food away from home.

\section{Methods}

The study design used in this research was crosssectional, carried out from November 2019 up to March 2020 among mothers of young children aged under-five and pre-school children. This study took place in Jakarta province, represented by Pejagalan urban village, located in Penjaringan Subdistrict, North Jakarta City. Jakarta Province was selected purposively as a representative of urban area in Indonesia which has a great proportion of slum areas. The subdistrict and the urban village were selected using a multistage random sampling. Meanwhile the subdistrict and the urban village was selected using a multistage random sampling. This area was considered to be an urban slum area which was flood-prone.

Consecutive sampling was applied in this study, in which all eligible subjects were enrolled until the minimum sample size was fulfilled. The subjects were chosen based on the children list obtained from randomly selected Posyandu (community health post). The data collection involved mothers who met the criteria as follows; aged 19-49 years, had a child aged 6 years old or younger, apparently healthy, fluent in Bahasa Indonesia, had the role as the primary food provider at home, and agreed to participate by signing the informed consent. Those who were pregnant, lactating, and under restrictive or specialized diet were excluded. Ethical approval was attained from the Ethical Committee of Faculty of Medicine, Universitas Indonesia No. ND- 
6/UN2.F1/ETIK/PPM.00.02/2020, dated 6 January 2020.

The sampling size was calculated using correlation formula with the $r$ coefficient referred to previous studies on health concern and dietary behavior., ${ }^{9,11}$ Considering the non-probability sampling used in this study, design effect of two was applied in order to increase the variation. The final sample size calculation also considered $80 \%$ of response rate, therefore it was added by $20 \%$ of the sample size as the non-response rate. The minimum sample size was determined to be 152 subjects with confidence level of $95 \%$ and power of $80 \%$.

Eligible subjects who gave their consent were visited for a face-to-face interview using a structured questionnaire. The data included sociodemographic, health concern, family food characteristics, and dietary assessment. Sociodemographic data comprised of subject's age, education level (elementary school, junior high school, senior high school, or university), employment status (unemployed, partially employed defined as working half-day or working at home (e.g. owning a small store at home), full-time employed defined as working full-day or at least eight hours a day), and average monthly household income.

Health concern questionnaire in this study referred to the General Health Interest Scale (GHIS), ${ }^{16}$ which was initially a self-administered questionnaire consisting of eight statements related to dietary behavior. The assessment is aimed to measure the degree of how health and nutrition is perceived as importance. This study had translated GHIS statements from English to Bahasa Indonesia and back-translated into English, followed with a preliminary interview with mothers with similar characteristics of the population and resulting in Cronbach's Alpha of 0.711 indicating good reliability. In this study, the self-administration approach was modified into interview, in which the interviewer read the statements and asked the subjects to rate each statement with 7-point Likert, from 0 to declare "strongly disagree" up to 6 to declare "strongly agree". Thus, the possible range for GHIS is 0-48. A higher score of GHIS indicated the higher degree of the subjects perceive health as importance.

Family food characteristics were explored by interviewing the subjects about cooking frequency, eating out frequency, and having take-out food or using food delivery services. This was a part of home food environment questionnaire, derived from a modified version of National Health and Nutrition Examination Survey Consumer Behavior Questionnaire $(\text { NHANES } \quad \mathrm{CBQ})^{17}$. This questionnaire was also translated into English and pre-tested among mothers with young children. It aimed to assess whether the subjects usually cook by themselves or purchase ready-to-eat food. For cooking frequency, it was determined by the number of days whether the subject or other household members cook (excluding cooking instant noodles or reheating commercially prepared food) in the previous week. While the frequency of eating out and having take-out food variable referred to the number of days the subjects purchased ready-to-eat food and/or eating out in the past one month.

Dietary assessment was conducted using 24-hour dietary recall in two non-consecutive days. The interviewer provided a food photobook to estimate the amount of food consumed. This study considered underreporting and overreporting energy intake with cut-off 500-3,500 kcal/day. ${ }^{18}$ Therefore those whose energy intake was under $500 \mathrm{kcal}$ and exceeding $3,500 \mathrm{kcal}$ were excluded from the analysis. Those who were not able to complete the second day of 24hour dietary recall were also excluded. Dietary data was analyzed using NutriSurvey for Windows Version 2007.

All statistical analysis in this study was performed using SPSS Version 20. For numerical data, normality test was conducted to determine the data distribution using Kolmogorov-Smirnov, which will be considered as normal distribution if P-value $>0.05$. Normally distributed data was displayed with mean and standard deviation (SD), whereas asymmetrically distributed data was displayed with median and interquartile range (IQR). Descriptive statistics were applied for sociodemographic characteristics (age, education level, employment status, and household income). Health concern, family food characteristics, and energy intake were compared by the sociodemographic characteristics using correlation Pearson or Spearman for continuous data, and Student t-test or MannWhitney for categorical data. Analysis to establish relationship between health concern, family food characteristics, and energy intake used Pearson or 
Spearman correlation. Statistical significance level was determined at $\mathrm{P}$-value $<0.05$.

\section{Results}

Total number of subjects participated in this study were 255 mothers. After calculating for underreporting energy intake and checking the completeness of the overall questionnaire, 22 subjects were excluded from the analysis. The subjects enrolled in this study exceeded the minimum sample size as it aimed to prevent removing too many subjects due to incompleteness and the possibility of underreporting energy intake. The socio-demographic characteristics of the subjects are displayed on Table 1. The median age of the subjects was 33 years old. Most of the subjects completed senior high school (35.6\%) and junior high school $(28.8 \%)$. Majority of the subjects were unemployed (housewives) $(68.2 \%)$. The median household monthly income was IDR 3 million (around USD 213.4 as of January 2021). Additionally, the majority of the subjects' households were categorized as low-middle income (76.4\%), which the third quartile was approximately the same amount of the regional minimum wage in Jakarta province as of 2020.

The GHIS total score resulted in median of 32 . Significant relationship was found between GHIS and subject's age $(\mathrm{r}=0.251$, P-value $<0.001)$. GHIS total score was slightly but significantly higher among the older age group compared to the younger one, which was 33 and 30 respectively. There was no significant difference in GHIS total score according to education level and household income.

Table 2 displayed the family food characteristics of the subjects. The cooking frequency showed the median of 6 days/week. Almost half of the subjects $(48.9 \%)$ always cooked meals at home, whereas only $15.9 \%$ never cooked. Significant difference of cooking frequency was only observed by the subject's age $(r=0.224$, P-value $=0.001)$, in which the older subjects cooked more frequently. There were no significant differences of cooking frequency by education level, employment status, and household income. Spearman correlation coefficient showed a significant relationship between GHIS total score and cooking frequency $(\mathrm{r}=0.235$, P- value $<0.01$ ), which means those who had greater health concern cooked more frequently. The median of the frequency of having food away from home was 0 for eating out and 8 for having take-out food. More than half of the subjects $(61.4 \%)$ never ate out in places like restaurants or food stalls in the past one month. Meanwhile, 33\% of the subjects had take-out food at least once a week and $36.9 \%$ of them had it more than once a week in the past one month. There was significant relationship between eating out $(\mathrm{r}=$ -0.277, P-value $<0.001)$ and having take-out food ( $\mathrm{r}$ $=-0.174, \mathrm{P}$-value $=0.008$ ) by age. We observed that eating out and having take-out food were more frequent among the younger subjects. By income, significant relationship was only observed on eating out frequency $(\mathrm{r}=0.265, \mathrm{P}$-value $<0.001)$. This shows that the higher household income was associated with more frequent eating out. Furthermore, we found that the greater health concern was associated with lower frequency of eating out $(\mathrm{r}=-0.171, \mathrm{P}$-value $<0.01)$ and having take-out food $(\mathrm{r}=-0.141, \mathrm{P}$-value $=0.032)($ Table 3).

The median of energy intake of the subjects was $1396 \mathrm{kcal} / \mathrm{day}$. The relationship between energy intake observed by age group, education level, employment status and household income were not found to be significant. Spearman correlation coefficient also did not show a significant relationship between health concern and energy intake, and between family food characteristics and energy intake (Table 3).

Multivariate analysis was performed with multiple linear regression using enter method and including all variables. Table 4 displayed the model with predictor of energy intake of the subjects. The overall model did not show statistical significance $(P$-value $=0.154)$. However, the frequency of having take-out food was a significant predictor of energy intake $(\beta=7.497$, P-value $=0.028)$. We found that every one day increase of having take-out food, energy intake of the subjects would increase by 7.5 kcal.

\section{Discussion}

The present study exhibits a similar result with the Indonesian TDS 2014, in which the energy intake of mothers was below the recommendation. The result 
of energy intake in this study was also consistent with previous studies among women in urban area. ${ }^{4,15}$ The subjects in this study were mothers of under-five and preschool-aged children. Previous findings in a study among parents stated that mothers with children displayed poorer dietary behavior and higher energy intake contributed from fat intake and consumption of sugar-sweetened beverages. ${ }^{19}$ Meanwhile, a Japanese study did not found significant difference of total energy intake between mothers with and without children. ${ }^{20}$ The dietary difference between parent and non-parent was apparently varied and tended to show no major changes. Nevertheless, it is worthy to note that becoming a mother was known to be associated with weight gain and increase in body mass index (BMI), making them more prone to obesity risk. ${ }^{21}$

The low energy intake among the subjects might be resulted from their eating habit. The subjects in our study generally had two or three meals per day, which one meal consisted of one serving of rice and less than half serving of vegetables as the side dishes, with one serving of protein source food or less, or even no protein at all. Consumption of instant noodles was also common. As we observed from the 24-hour dietary recall, snacking habit among the subjects was varied. The prevalent snacking habit among female adolescents contributed to meal-skipping. ${ }^{22}$ Nonetheless, the characteristics differences between adolescents and mothers may play a big role in determining the snacking habit. Similar with other Indonesian studies, ${ }^{7,15,22}$ fried food and cilok (ball-shaped boiled tapioca flour) were the common snacks consumed by the subjects of this study. Among our subjects, consuming sugar-sweetened beverages seemed to be a part of their daily lifestyle. It was recommended to limit intake from empty calorie food which only provide calories but few or no nutrients, including from sugar-sweetened beverages. According to U.S. Department of Agriculture (USDA), intake limits differed by age and sex. ${ }^{23}$ Several diet quality measures determined the limit for these food groups to achieve a good diet. Healthy Eating Index $2010^{24}$ set the intake limit not more than $20 \%$ of energy intake, while Diet Quality Index-International ${ }^{25}$ set it not more than $10 \%$. At least half of the subjects had more than $10 \%$ of energy intake contributed from empty calorie food. Despite the considerable contribution from fried snacks and sugar-sweetened beverages, the food choice and the amount of foods consumed from the main meals were not sufficient to achieve the recommended energy intake.

In this study, significant relationship between health concern and energy intake was not established. However, the negative correlation implied that the higher health concern was related to lower energy intake. A study in Luxemburg found a significant difference in energy intake based on the importance level of nutrition and balanced meals. Similarly, those who perceived nutrition as highly important displayed lower energy intake. The different measure to assess health concern might explain how the results on significance were not in line. Alkerwi et al. ${ }^{26}$ used a single question focusing on balanced meals with 3-level of classification from low, moderate, and high. A single question might help the respondents to categorize themselves into respective categories since it was more straightforward. In contrast, we used an instrument comprised of eight statements which had larger scope, including eating behavior, food choice, and balanced diet. Unfortunately, studies about health concern and energy intake was rare. Nevertheless, the existing literatures supported that greater health concern was related to healthier eating behavior ${ }^{9}$ and dietary pattern ${ }^{27}$.

Based on the multiple linear regression model, having take-out food was found to be a significant predictor of energy intake. Interestingly, health concern was significantly correlated with frequency of having take-out food. Our result suggested that the greater concern towards health, the less frequent the subjects to purchase take-out food. According to a qualitative study among mothers, in the context of household with children, the mothers usually prioritized health and nutrition concern when providing food for the family. ${ }^{28}$ For some mothers, given the limited facilities to store fresh foods at home and time constraint for preparation and cooking, they might think differently when it comes to provide food for themselves. It was more likely that they allocated more time to perform house chores, drop off and pick up older children from school, and take care of the young children, resulting to have take-out food as a practical way to fulfil their dietary needs. ${ }^{8}$ Among our subjects, we observed that take-out food in the form of side dishes like 
cooked vegetables or fried foods were meant to be consumed for the whole family members, since the mothers usually only cooked rice. Meanwhile, takeout food that was consumed by the mothers only was typically one-dish meal (e.g. meatball soup, noodles, nasi uduk).

Our result also showed a significant positive correlation between health concern and frequency of cooking at home, which the greater health concern was associated with more frequent cooking. In contrast, the greater health concern was related to the less frequent of eating out. This result was consistent with a study in Brazil. Those who perceived high concern towards health would be more engaged in their meal planning, food choice, and the cooking methods. ${ }^{13}$ Various food stores were abundant in urban slum neighborhood, which mostly provided cooked meals (e.g. rice, vegetable side dishes, fried chicken or fish, soto, etc) or snack (e.g. fried vegetable fritters), manufactured snack and beverages. ${ }^{7,8}$ When food stores were available and easily accessed, this may contribute to more eating out or having take-out, rather than cooking. ${ }^{29}$ Although purchasing cooked meals was common in urban slum area, our result found that more than half of the subjects frequently cooked and prepared their meals at home. Cooking at home can be seen as a challenge due to time and cost. Nonetheless, cooking by themselves was preferred by particular women who wanted to ensure the hygiene of the food preparation process. ${ }^{8}$

Apparently, eating out was not common, except for the working mothers. We assumed that eating out was considered as a family leisure activity. In spite of the abundant food stores available, the space provided in the food stalls in a densely populated neighborhood was not suitable for family with young children. In addition, for the low socioeconomic status (SES) community, the term eating out was seen as a luxurious activity (i.e. eating in a restaurant), thus it can be economically challenging. Price is commonly discussed and often perceived as barrier to healthy diet. This study found a significant positive correlation between household income and eating out frequency. This may suggest that the expenditure might be higher as the frequency increases. Previous studies highlighted how socioeconomic status may influence diet through food choices. It was generally believed that higher SES had greater food expenditure, resulting in a healthier food choice. ${ }^{30}$

Consuming meals that are prepared away from home, including eating out and having take-out, was considered to be less healthy. A Korean study demonstrated a significant different diet between those who eat homemade meals and non-homemade meals. Homemade meals were associated with lower energy intake, with more dishes consisted of grains. The cooking methods used was mainly stewing or steaming. ${ }^{31}$ This result displayed similarity to ours although it was not statistically significant, the inverse correlation showed the tendency of the more frequent cooking, the lower energy intake. The subjects in our study who frequently cooked mostly had vegetables soup in their menu. On the contrary, those who eat non-homemade meals demonstrated more diverse food and meat-based dish, contributing to higher protein intake. ${ }^{31}$ Our results demonstrated a positive correlation between eating out and takeout food towards energy intake. As stated by Lee et al. ${ }^{31}$ food away from home was related to more various cooking methods. We observed the food stores in the neighborhood provided numerous choices of food, such as fried food, stir-fry food, coconut-based soup, which might explain how these foods can contribute to higher energy intake. Our multivariate analysis also exhibited that for every one-day increase of having take-out food, energy intake of the mothers would increase by $7.5 \mathrm{kcal}$ as well. Although it is statistically significant, this number is not clinically significant since $7.5 \mathrm{kcal}$ is less than $1 \%$ of Indonesian RDI for energy intake for women of reproductive age.

This study had some limitations that should be noted. Underreporting energy intake was not using actual calculation with consideration of individual nutritional status. Several attempts to calculate under-reporting energy intake using the established body weight and height in Indonesian dietary recommendation was done, yet the result would exclude more than half of the subjects. Thus, cut-off 500-3500 kcal was used. ${ }^{18}$ Secondly, we applied the general rules of thumb to determine minimum sample size for multiple linear regression analysis, yet our sample of 233 participants (which is more than the minimum number of samples based on the calculation, i.e. 152) was still underpowered to detect significance in predicting the energy intake. 
Our findings suggested that frequent take-out food was associated with higher energy intake. The median energy intake who never had take-out food was $1355 \mathrm{kcal} /$ day, meanwhile those who had takeout food at least once a week had slightly higher median energy intake of $1407.5 \mathrm{kcal} /$ day. Previous studies show that take-out food and other forms of food away from home were also associated with higher intake of sodium and fat, ${ }^{32}$ higher BMI, ${ }^{33}$ and increasing odds of overweight/obesity ${ }^{34}$. Therefore, the findings in this study should be cautiously interpreted, given that most of our subjects' energy intake was below recommendation. As there are various food options provided in the neighborhood food stores, behavior of having take-out food can be modified through an intervention program focusing on giving understanding about healthy food choice along with improving food preparation skill. Furthermore, education on food choice and homeprepared food with relation to expenditure might be more insightful for the mothers, particularly in low SES community.

The negative correlation between health concern and frequency of take-out food suggested that our subjects had fair understanding about the healthiness of food. However, the abundant food stores can be a driver to frequent consumption of food away from home. ${ }^{35}$ The external environment factors such as food stores availability and accessibility are less modifiable. Instead, providing sufficient information about the healthiness of food and motivating messages in the food store might help the consumer to consider their food choice. A review of small store-based intervention suggested that combined strategies in physical environment in food stores (e.g. food placement) and behavioral involving both sellers and consumers (e.g. poster) might improve the access and the consumption of nutritious food. ${ }^{36}$ This would require a collaboration involving local government, health officials, cadres, and the food sellers in order to establish behavior changes to achieve a better diet. Empowering both consumers and food sellers is a crucial step to enable them to make a better and healthier choice to provide food for themselves and for the family.

Table 1. Demographic characteristics of mothers of young children in Pejagalan, North Jakarta $(n=233)$

\begin{tabular}{|c|c|c|c|}
\hline Variables & Median (IQR) & $\mathbf{n}$ & $\%$ \\
\hline Age (years old) & $33.0(9.0)$ & & \\
\hline 19-29 years old & & 75 & 32.2 \\
\hline $30-49$ years old & & 158 & 67.8 \\
\hline \multicolumn{4}{|l|}{ Education level } \\
\hline Less than elementary school & & 12 & 5.2 \\
\hline Elementary school graduate & & 64 & 27.5 \\
\hline Junior high school graduate & & 67 & 28.8 \\
\hline Senior high school graduate & & 83 & 35.6 \\
\hline Diploma / university graduate & & 7 & 3.0 \\
\hline \multicolumn{4}{|l|}{ Employment status } \\
\hline Unemployed (housewife) & & 159 & 68.2 \\
\hline Partially employed & & 46 & 19.7 \\
\hline Fully employed & & 28 & 12.0 \\
\hline Average monthly household income (IDR) & 3 million $(1.950 \text { million })^{1}$ & & \\
\hline Low-middle ( $\leq 3^{\text {rd }}$ quartile $)$ & & 178 & 76.4 \\
\hline High $\left(>3^{\text {rd }}\right.$ quartile) & & 55 & 23.6 \\
\hline
\end{tabular}

IQR : Interquartile range, IDR: Indonesian Rupiah

${ }^{1} 1 \mathrm{USD}=$ IDR $14,058.6$ as of January 15, 2021 
Table 2. Family food characteristics of mothers with young children in Pejagalan, North Jakarta $(n=233)$

\begin{tabular}{lccc}
\hline Variables & Median (IQR) & n & \% \\
\hline Cooking frequency (days) $^{\mathrm{a}}$ & $6(5)$ & & \\
Never & & 37 & 15.9 \\
$1-3$ days/week & & 53 & 22.7 \\
$4-6$ days/week & & 29 & 12.4 \\
Always (7 days/week) & $0(3)$ & 114 & 48.9 \\
Eating out frequency (days) & & & \\
Never & & 143 & 61.4 \\
$1-3$ days/month & & 34 & 14.6 \\
$1-3$ days/week & $8(18)$ & 35 & 15.0 \\
More than 4 days/week & & 21 & 9.0 \\
Having take-out food frequency (days) & & & \\
Never & & 23 & 9.9 \\
$1-3$ days/month & & 47 & 20.2 \\
$1-3$ days/week & & 77 & 33.0 \\
More than 4 days/week & & 86 & 36.9 \\
\hline
\end{tabular}

IQR : Interquartile range; ${ }^{a}$ Number of days in the past one week; ${ }^{b}$ Number of days in the past one month

Table 3. Correlation between health concern, family food characteristics, and energy intake

\begin{tabular}{|c|c|c|c|c|c|c|c|c|c|c|}
\hline \multirow[t]{2}{*}{ Variables } & \multirow{2}{*}{\multicolumn{2}{|c|}{$\begin{array}{c}\text { Health } \\
\text { concern } \\
r \quad P \text {-value }{ }^{a}\end{array}$}} & \multicolumn{2}{|c|}{$\begin{array}{l}\text { Cooking } \\
\text { frequency }\end{array}$} & \multicolumn{2}{|c|}{$\begin{array}{l}\text { Eating out } \\
\text { frequency }\end{array}$} & \multicolumn{2}{|c|}{$\begin{array}{l}\text { Take-out food } \\
\text { frequency }\end{array}$} & \multicolumn{2}{|c|}{ Energy intake } \\
\hline & & & $r$ & $P$-value ${ }^{a}$ & $r$ & $\begin{array}{c}P- \\
\text { value }^{a}\end{array}$ & $r$ & $P$-value ${ }^{a}$ & $r$ & $P$-value $^{a}$ \\
\hline Health concern & 1 & . & $\begin{array}{c}0.23 \\
5\end{array}$ & $<0.001 *$ & -0.171 & $0.009^{*}$ & -0.141 & $0.032^{*}$ & -0.067 & 0.309 \\
\hline $\begin{array}{l}\text { Cooking frequency } \\
\text { (days) }^{\mathrm{b}}\end{array}$ & & & 1 & & -0.186 & $0.004^{*}$ & -0.602 & $<0.001^{*}$ & -0.019 & 0.773 \\
\hline $\begin{array}{l}\text { Eating out frequency } \\
\text { (days) }^{\mathrm{c}}\end{array}$ & & & & & 1 & . & 0.249 & $<0.001 *$ & 0.097 & 0.141 \\
\hline $\begin{array}{l}\text { Having take-out food } \\
\text { frequency (days) }\end{array}$ & & & & & & & 1 & . & 0.093 & 0.157 \\
\hline Energy intake (kcal) & & & & & & & & & 1 & \\
\hline
\end{tabular}

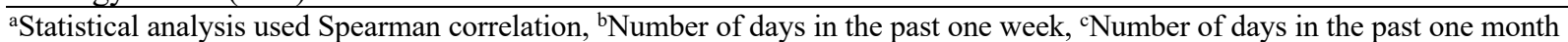

*Significance level of $P$-value $<0.05$ 
Table 4. Multiple linear regression model for predictor of energy intake $(n=233)$

\begin{tabular}{|c|c|c|c|}
\hline Variables & Beta coefficient & SE & $P$-value \\
\hline Age (years old) & 1.804 & 5.188 & 0.728 \\
\hline Education level $^{\mathrm{a}}$ & 38.058 & 32.128 & 0.237 \\
\hline Employment status ${ }^{\mathrm{b}}$ & 135.963 & 69.895 & 0.053 \\
\hline Household income (IDR) & $<0.001$ & 0.00 & 0.222 \\
\hline Health concern & -2.366 & 4.045 & 0.559 \\
\hline Cooking frequency (days) ${ }^{\mathrm{c}}$ & 11.649 & 13.784 & 0.845 \\
\hline Eating out frequency (days) ${ }^{\mathrm{d}}$ & 4.927 & 4.640 & 0.289 \\
\hline Take-out food frequency (days) ${ }^{\mathrm{d}}$ & 7.497 & 3.380 & $0.028^{*}$ \\
\hline
\end{tabular}

IDR: Indonesian Rupiah, SE: Standard Error

${ }^{a}$ Education level referred to five-level education attainment from diploma/university, senior high school, junior high school, elementary school, and less than elementary school; ${ }^{b}$ Employment status referred to employed and unemployed; ${ }^{\circ}$ Number of days in the past one week; ${ }^{\mathrm{d}}$ Number of days in the past one month; *Significance level at $P$-value $<0.05$

Multiple linear regression was performed using enter method including all variables altogether

R square $=0.051, P$-value $=0.154$

\section{Conflict of Interest}

Authors declared no conflict of interest regarding this article.

\section{Acknowledgment}

We would like to thank the officials from Pejagalan Primary Healthcare Center, Posyandu cadres, all participants, and our field officers in Pejagalan urban village who participated in this study.

\section{Open Access}

This article is distributed under the terms of the Creative Commons Attribution 4.0 International Licence

(http://creativecommons.org/licenses/by/4.0/), which permits unrestricted use, distribution, and reproduction in any medium, provided you give appropriate credit to the original author(s) and the source, provide a link to the Creative Commons license, and indicate if changes were made.

\section{References}

1. GBD 2017 Diet Collaborators. Health effects of dietary risks in 195 countries, 1990-2017: a systematic analysis for the Global Burden of Disease Study 2017. Lancet. 2019;393:1958-72.

2. Development Initiative. Global Nutrition Report 2018: shining a light to spur action on nutrition. Bristol, UK;
2018.

3. Caulfied LE, Victoria Elliot, Program in Human Nutrition, Health the JHBS of PH, for SPRING. Nutrition of Adolescent Girls and Women of Reproductive Age in Low- and Middle-Income Countries: Current Context and Scientific Basis for Moving Forward. Arlington, VA; 2015.

4. Madanijah S, Briawan D, Rimbawan R, Zulaikhah Z, Andarwulan N, Nuraida L, et al. Nutritional status of pre-pregnant and pregnant women residing in Bogor district, Indonesia: a cross-sectional dietary and nutrient intake study. Br J Nutr. 2016;116:1-10.

5. Siswanto. Total Diet Study: Individual Food Consumption Survey Indonesia 2014. Jakarta: NIHRD Publisher; 2014.

6. Kueppers J, Stein KF, Groth S, Fernandez ID. Maternal and child dietary intake: The role of maternal healthyeater self-schema. Appetite. 2018;125:527-36.

7. Anggraini R, Februhartanty J, Bardosono S, Khusun H, Worsley A. Food store choice among urban slum women is associated with consumption of energy-dense food. Asia Pacific J Public Heal. 2016;28(5):458-68.

8. Sufyan D, Februhartanty J, Bardosono S, Khusun H, Ermayani E, Rachman PH, et al. Food purchasing behaviour among urban slum women in East Jakarta: A qualitative study. Malays J Nutr. 2019;25:S33-46.

9. Botchway I, Wiafe-Akenteng B, Atefoe EA. Health consciousness and eating habits among non-medical students in Ghana: a cross-sectional study. J Advocacy, Res Educ. 2015;2(1):31-5.

10. Czerwińska M, Maciejewska D, Ryterska K, Pablo S-F, Jakubczyk K, Banaszczak M, et al. The health concern scale: what results does the analysis of this scale bring in a population of young participants of a music festival? J Nutr Food Sci. 2016;6(5).

11. Bogue J, Coleman T, Sorenson D. Determinants of consumers' dietary behaviour for health-enhancing 
foods. Br Food J. 2005;107(1):4-16.

12. Sun Y-HC. Health concern, food choice motives, and attitudes toward healthy eating: The mediating role of food choice motives. Appetite. 2008;51(1):42-9.

13. de Camargo AM, Botelho AM, Dean M, Fiates GMR. Meal planning by high and low health conscious individuals during a simulated shop in the supermarket: A mixed methods study. Appetite. 2020;144:104468.

14. Dewayani N, Sukihananto. Relationship between maternal knowledge of balanced nutritional guidelines and snack food selection by school-aged children at school. Enfermería Clínica. 2018;28(Supl 1 Part B):280-4.

15. Yulia, Khusun H, Fahmida U. Dietary patterns of obese and normal-weight women of reproductive age in urban slum areas in Central Jakarta. Br J Nutr. 2016;116:1-8.

16. Roininen K, Lähteenmäki L, Tuorila H. Quantification of consumer attitudes to health and hedonic characteristics of foods. Appetite. 1999;33(1):71-88.

17. CDC. NHANES 2009-2010 Questionnaire Instruments [Internet]. 2010 [cited 2019 Oct 11].

Available from:

https://wwwn.cdc.gov/nchs/data/nhanes/2009-

2010/questionnaires/cbq_f_eng.pdf

18. Willet W. Nutritional Epidemiology. Third Edit. New York: Oxford University Press; 2013.

19. Berge JM, Larson N, Bauer KW, Neumark-Sztainer D. Are parents of young children practicing healthy nutrition and physical activity behaviors? Pediatrics. 2011;127(5):881-7.

20. Saito A, Matsumoto M, Hyakutake A, Saito M, Okamoto N. The presence of children in households was associated with dietary intake among Japanese married women: the POTATO study. J Nutr Sci. 2018;7(16):1-9.

21. Corder K, Winpenny EM, Foubister C, Guagliano JM, Hartwig XM, Love R, et al. Becoming a parent: A systematic review and meta-analysis of changes in BMI, diet, and physical activity. Obes Rev. 2020;21(4):e12959.

22. Blum LS, Mellisa A, Kurnia Sari E, Novitasari Yusadiredja I, van Liere M, Shulman S, et al. In-depth assessment of snacking behaviour in unmarried adolescent girls 16-19 years of age living in urban centres of Java, Indonesia. Matern Child Nutr. 2019;15(4):1-12.

23. Dietary Guidelines Advisory Committee. Scientific Report of the 2015 Dietary Guidelines Advisory Committee: Advisory Report to the Secretary of Health and Human Services and the Secretary of Agriculture. Washington, DC; 2015.

24. Guenther PM, Casavale KO, Reedy J, Kirkpatrick SI, Hiza HAB, Kuczynski KJ, et al. Update of the Healthy Eating Index: HEI-2010. J Acad Nutr Diet. 2013;113(4):569-80.

25. Kim S, Haines PS, Siega-Riz AM, Popkin BM. The Diet Quality Index-International (DQI-I) provides an effective tool for cross-national comparison of diet quality as illustrated by China and the United States. J
Nutr. 2003;133(11):3476-84.

26. Alkerwi A, Sauvageot N, Malan L, Shivappa N, Hébert JR. Association between nutritional awareness and diet quality: Evidence from the observation of cardiovascular risk factors in Luxembourg (ORISCAVLUX) study. Nutrients. 2015;7(4):2823-38.

27. Jezewska-Zychowicz M, Wadolowska L, Kowalkowska J, Lonnie M, Czarnocinska J, BabiczZielinska E. Perceived health and nutrition concerns as predictors of dietary patterns among polish females aged 13-21 years (GEBaHealth project). Nutrients. 2017;9(6).

28. Raskind IG, Woodruff RC, Ballard D, Cherry ST, Daniel S, Haardörfer R, et al. Decision-making processes shaping the home food environments of young adult women with and without children. Appetite. 2017;113:124-33.

29. Thorpe MG, Kestin M, Riddell LJ, Keast RS, McNaughton SA. Diet quality in young adults and its association with food-related behaviours. Public Health Nutr. 2014;17(8):1767-75.

30. Pechey R, Monsivais P. Socioeconomic inequalities in the healthiness of food choices: Exploring the contributions of food expenditures. Prev Med (Baltim). 2016;88:203-9.

31. Lee KW, Song WO, Cho MS. Dietary quality differs by consumption of meals prepared at home vs. outside in Korean adults. Nutr Res Pract. 2016;10(3):294-304.

32. Zang J, Luo B, Wang Y, Zhu Z, Wang Z, He X, et al. Eating out-of-home in adult residents in Shanghai and the nutritional differences among dining places. Nutrients. 2018;10(7):951.

33. Bhutani S, Schoeller DA, Walsh MC, McWilliams C. Frequency of eating out at both fast-food and sit-down restaurants was associated with high body mass index in non-large metropolitan communities in Midwest. Am J Heal Promot. 2018;32(1):75-83.

34. McClain AC, Ayala GX, Sotres-Alvarez D, Siega-Riz AM, Kaplan RC, Gellman MD, et al. Frequency of intake and type of away-from- home foods consumed are associated with diet quality in the hispanic community health study/study of latinos (HCHS/SOL). J Nutr. 2018;148(3):453-63.

35. Janssen HG, Davies IG, Richardson LD, Stevenson L. Determinants of takeaway and fast food consumption: a narrative review. Nutr Res Rev. 2017;(8):1-19.

36. Gittelsohn J, Rowan M, Gadhoke P. Interventions in small food stores to change the food environment, improve diet, and reduce risk of chronic disease. Prev Chronic Dis. 2012;9(2):1-15. 